\title{
Towards Translation of Discrete Frequency Infrared Spectroscopic Imaging for Rapid Digital Histopathology of Clinical Biopsy Samples
}

Saumya Tiwari, ${ }^{1}$ Jai Raman, ${ }^{2}$ Vijaya Reddy ${ }^{3}$ Andrew Ghetler, ${ }^{4}$ Richard P. Tella, ${ }^{4}$ Yang Han, ${ }^{4}$ Christopher R. Moon, ${ }^{4}$ Charles D. Hoke, ${ }^{4}$ Rohit Bhargava*

${ }^{1}$ Department of Bioengineering and Beckman Institute for Advanced Science and Technology, University of Illinois at Urbana Champaign, Urbana, Illinois 61801, USA.

${ }^{3}$ Department of Pathology, Rush University Medical Center, 1725 West Harrison St, Chicago, Illinois 60612, USA.

${ }^{2}$ Advanced Heart Failure Transplantation \& Mechanical Circulatory Support, Rush University Medical Center, 1725 West Harrison St, Chicago, Illinois 60612, USA.

${ }^{4}$ California Research Center, Spectroscopy \& Vacuum Solutions Division, Agilent Technologies, Inc., 5301 Stevens Creek Blvd., Santa Clara, CA 95051 USA

${ }^{5}$ Departments of Chemistry, Mechanical Science and Engineering, Chemical and Biomolecular Engineering, Electrical and Computer Engineering, Beckman Institute for Advanced Science and Technology, University of Illinois at Urbana-Champaign, Urbana, Illinois 61801, USA.

*Author to whom correspondence should be addressed. Email: rxb@illinois.edu 


\section{- Title of primary article}

\section{Towards Translation of Discrete Frequency Infrared Spectroscopic Imaging for Rapid Digital Histopathology of Clinical Biopsy Samples}

\section{- Abstract}

Fourier transform infrared (FT-IR) spectroscopic imaging has been widely tested as a tool for stainless digital histology of biomedical specimens, including for identification of infiltration and fibrosis in endomyocardial biopsy samples to assess transplant rejection. A major barrier in clinical translation has been the slow speed of imaging. To address this need, we tested and report here the viability of using high speed discrete frequency infrared (DFIR) imaging to obtain stain-free biochemical imaging in cardiovascular samples collected from patients. Images obtained by this method were classified with high accuracy by a Bayesian classification algorithm trained on FT-IR imaging data as well as on DFIR data. A single spectral feature correlated with instances of fibrosis, as identified by the pathologist, highlighting the advantage of the DFIR imaging approach for rapid detection. The speed of digital pathologic recognition was at least 16 times faster than the fastest FT-IR imaging instrument. These results indicate that a fast, on-site identification of fibrosis using IR imaging has potential for real time assistance during surgeries. Further, the work describes development and applications of supervised classifiers on DFIR imaging data, comparing classifiers developed on FT-IR and DFIR imaging modalities and identifying specific spectral features for accurate identification of fibrosis. This addresses a topic of much debate on the use of training data and crossmodality validity of IR measurements. Together, the work is a step towards addressing a clinical diagnostic need at acquisition time scales that make IR imaging technology practical for medical use. 
- Table of contents that describes the nature of the materials therein.

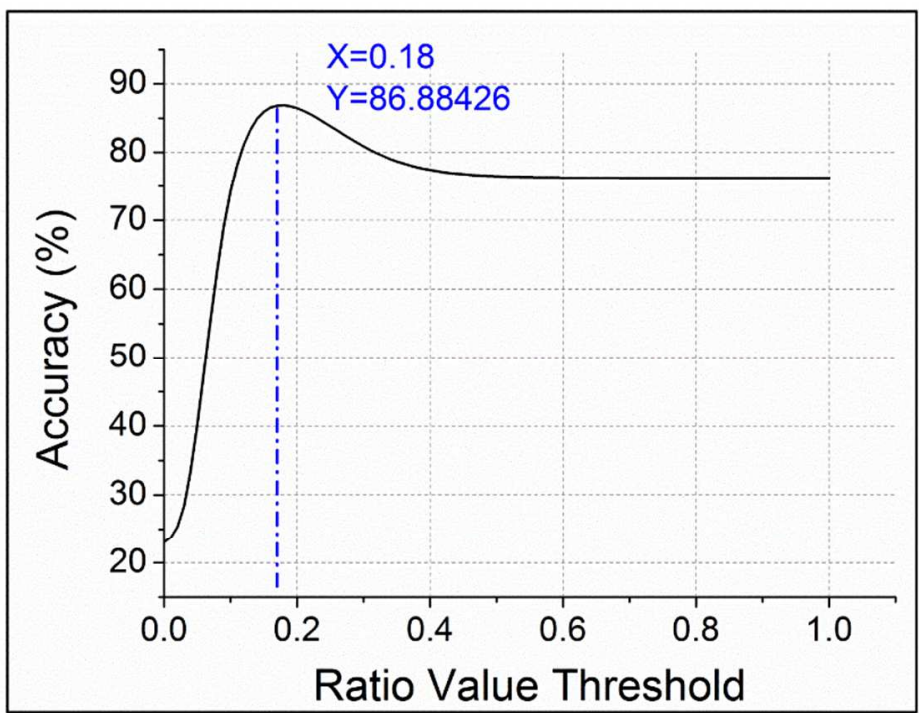

Supplementary figure 1: Optimal threshold identification. Shown here is the threshold identification for peak height ratio of $1236 \mathrm{~cm}^{-1}$ and $1542 \mathrm{~cm}^{-1}$ after fine tuning the ratio value threshold. 
Supplementary Table 1. Metrics used in FT-IR imaging based classifier in the order of addition

\begin{tabular}{|c|c|c|}
\hline Metric type & Feature 1 & Feature 2 \\
\hline Peak height ratio & $1389 \mathrm{~cm}^{-1}$ & $1236 \mathrm{~cm}^{-1}$ \\
\hline Peak area to height ratio & $1274 \mathrm{~cm}^{-1}$ to $1543 \mathrm{~cm}^{-1}$ & $1652 \mathrm{~cm}^{-1}$ \\
\hline Peak height ratio & $1239 \mathrm{~cm}^{-1}$ & $1543 \mathrm{~cm}^{-1}$ \\
\hline Peak height ratio & $1339 \mathrm{~cm}^{-1}$ & $1543 \mathrm{~cm}^{-1}$ \\
\hline Peak height ratio & $1236 \mathrm{~cm}^{-1}$ & $1543 \mathrm{~cm}^{-1}$ \\
\hline Peak height ratio & $1389 \mathrm{~cm}^{-1}$ & $1452 \mathrm{~cm}^{-1}$ \\
\hline Center of gravity & $1482 \mathrm{~cm}^{-1}$ & $1594 \mathrm{~cm}^{-1}$ \\
\hline Peak area to height ratio & $1324 \mathrm{~cm}^{-1}$ to $1358 \mathrm{~cm}^{-1}$ & $1652 \mathrm{~cm}^{-1}$ \\
\hline Peak height ratio & $1405 \mathrm{~cm}^{-1}$ & $1236 \mathrm{~cm}^{-1}$ \\
\hline Peak area to height ratio & $1482 \mathrm{~cm}^{-1}$ to $1594 \mathrm{~cm}^{-1}$ & $1652 \mathrm{~cm}^{-1}$ \\
\hline Peak height ratio & $1027 \mathrm{~cm}^{-1}$ & $1236 \mathrm{~cm}^{-1}$ \\
\hline Center of gravity & $1048 \mathrm{~cm}^{-1}$ & $1070 \mathrm{~cm}^{-1}$ \\
\hline Peak height ratio & $1389 \mathrm{~cm}^{-1}$ & $1065 \mathrm{~cm}^{-1}$ \\
\hline
\end{tabular}


Supplementary table 2: Metrics used in DFIR imaging based classifier in the order of addition, accuracy percentage is the accuracy obtained at each metric individually at optimized threshold values

\begin{tabular}{|c|c|c|c|}
\hline Metric type & Feature 1 & Feature 2 & $\begin{array}{c}\text { Accuracy } \\
\text { (\%) }\end{array}$ \\
\hline Peak height ratio & $1038 \mathrm{~cm}^{-1}$ & $1542 \mathrm{~cm}^{-1}$ & 78.821 \\
\hline Peak area to height ratio & $1482 \mathrm{~cm}^{-1}$ to $1590 \mathrm{~cm}^{-1}$ & $1038 \mathrm{~cm}^{-1}$ & 70.09 \\
\hline Peak area to height ratio & $996 \mathrm{~cm}^{-1}$ to $1140 \mathrm{~cm}^{-1}$ & $1542 \mathrm{~cm}^{-1}$ & 79.712 \\
\hline Peak height ratio & $1236 \mathrm{~cm}^{-1}$ & $1542 \mathrm{~cm}^{-1}$ & 86.46 \\
\hline Peak area to height ratio & $1482 \mathrm{~cm}^{-1}$ to $1590 \mathrm{~cm}^{-1}$ & $1236 \mathrm{~cm}^{-1}$ & 76.24 \\
\hline Peak area to height ratio & $1182 \mathrm{~cm}^{-1}$ to $1290 \mathrm{~cm}^{-1}$ & $1542 \mathrm{~cm}^{-1}$ & 81.831 \\
\hline Peak area to height ratio & $1482 \mathrm{~cm}^{-1}$ to $1710 \mathrm{~cm}^{-1}$ & $1236 \mathrm{~cm}^{-1}$ & 76.203 \\
\hline Peak height ratio & $1236 \mathrm{~cm}^{-1}$ & $1650 \mathrm{~cm}^{-1}$ & 85.185 \\
\hline Peak area to height ratio & $1182 \mathrm{~cm}^{-1}$ to $1290 \mathrm{~cm}^{-1}$ & $1650 \mathrm{~cm}^{-1}$ & 80.239 \\
\hline Peak height ratio & $1074 \mathrm{~cm}^{-1}$ & $1650 \mathrm{~cm}^{-1}$ & 72.031 \\
\hline Peak area to height ratio & $1482 \mathrm{~cm}^{-1}$ to $1590 \mathrm{~cm}^{-1}$ & $1020 \mathrm{~cm}^{-1}$ & 53.126 \\
\hline
\end{tabular}


Supplementary table 3: Metrics used in multi-class DFIR imaging based classifier in the order of addition

\begin{tabular}{|c|c|c|}
\hline Metric type & Feature 1 & Feature 2 \\
\hline Peak area to height ratio & $1362 \mathrm{~cm}^{-1}$ to $1428 \mathrm{~cm}^{-1}$ & $1650 \mathrm{~cm}^{-1}$ \\
\hline Peak area to height ratio & $1482 \mathrm{~cm}^{-1}$ to $1590 \mathrm{~cm}^{-1}$ & $1038 \mathrm{~cm}^{-1}$ \\
\hline Peak area to area ratio & $1428 \mathrm{~cm}^{-1}$ to $1482 \mathrm{~cm}^{-1}$ & $1590 \mathrm{~cm}^{-1}$ to $1710 \mathrm{~cm}^{-1}$ \\
\hline Peak area to height ratio & $1482 \mathrm{~cm}^{-1}$ to $1710 \mathrm{~cm}^{-1}$ & $1464 \mathrm{~cm}^{-1}$ \\
\hline Peak height ratio & $1038 \mathrm{~cm}^{-1}$ & $1398 \mathrm{~cm}^{-1}$ \\
\hline Peak area to height ratio & $1482 \mathrm{~cm}^{-1}$ to $1710 \mathrm{~cm}^{-1}$ & $1236 \mathrm{~cm}^{-1}$ \\
\hline Peak area to area ratio & $1362 \mathrm{~cm}^{-1}$ to $1428 \mathrm{~cm}^{-1}$ & $1590 \mathrm{~cm}^{-1}$ to $1710 \mathrm{~cm}-1$ \\
\hline Peak height ratio & $1236 \mathrm{~cm}^{-1}$ & $1464 \mathrm{~cm}^{-1}$ \\
\hline Peak area to height ratio & $1482 \mathrm{~cm}^{-1}$ to $1590 \mathrm{~cm}^{-1}$ & $1236 \mathrm{~cm}^{-1}$ \\
\hline Peak height ratio & $1482 \mathrm{~cm}^{-1}$ & $1650 \mathrm{~cm}^{-1}$ \\
\hline Peak area to area ratio & $1482 \mathrm{~cm}^{-1}$ to $1590 \mathrm{~cm}^{-1}$ & 1590 to $1710 \mathrm{~cm}^{-1}$ \\
\hline Peak area to height ratio & $1482 \mathrm{~cm}^{-1}$ to $1590 \mathrm{~cm}^{-1}$ & $1020 \mathrm{~cm}^{-1}$ \\
\hline Peak area to area ratio & $1362 \mathrm{~cm}^{-1}$ to $1482 \mathrm{~cm}^{-1}$ & $1590 \mathrm{~cm}^{-1}$ to $1710 \mathrm{~cm}^{-1}$ \\
\hline Peak height ratio & $1020 \mathrm{~cm}^{-1}$ & $1398 \mathrm{~cm}^{-1}$ \\
\hline Peak area to height ratio & $996 \mathrm{~cm}^{-1}$ to $1140 \mathrm{~cm}^{-1}$ & $1542 \mathrm{~cm}^{-1}$ \\
\hline Peak area to area ratio & $996 \mathrm{~cm}^{-1}$ to $1140 \mathrm{~cm}^{-1}$ & $1590 \mathrm{~cm}^{-1}$ to $1710 \mathrm{~cm}^{-1}$ \\
\hline Peak area to height ratio & $1362 \mathrm{~cm}^{-1}$ to $1428 \mathrm{~cm}^{-1}$ & $1020 \mathrm{~cm}^{-1}$ \\
\hline Peak area to height ratio & $1482 \mathrm{~cm}^{-1}$ to $1710 \mathrm{~cm}^{-1}$ & $1038 \mathrm{~cm}^{-1}$ \\
\hline
\end{tabular}

